\title{
Assessment of Immunization Status of Children between 12-23 Months in
}

\section{Bareilly District}

\author{
Joshi H S1, Gupta R², Singh A3 , Mahajan V4
}

${ }^{1}$ Associate Professor, Department of Community Medicine, Rohilkhand Medical College \& Hospital, Bareilly, UP, India

${ }^{2}$ Associate Professor, Department of Anatomy, Rohilkhand Medical College \& Hospital,Bareilly, UP, India.

${ }^{3}$ Assistant Professor, Department of Community Medicine, Rohilkhand Medical College \& Hospital, Bareilly, UP, India.

${ }^{4}$ Ex- Medical Officer, Department of Community Medicine, Rohilkhand Medical College \& Hospital, Bareilly, UP, India.

\section{Original Article}

\section{Corresponding Author:}

Dr. HS Joshi, MD

Associate Professor,

Department of Community Medicine,

Rohilkhand Medical College \& Hospital,

Bareilly, UP, India.

Email:drjoshiharish@rediffmail.com

\section{Abstract}

\section{Objectives}

To assess the immunization status of children in the age group 12-23 months and to know the reasons for nonimmunization of children.

\section{Materials and Methods}

A cross-sectional survey was conducted using WHO's thirty cluster sampling technique in rural and urban areas of Bareilly district from August 2008 to January 2009. Rural areas were divided into blocks and blocks were divided into villages. Urban areas were divided into wards. Villages and wards were taken as clusters. During the house-to-house survey, a total of 240 children of age 12-23 months were included in the present study.

\section{Results}

Only around $50 \%$ of children were fully immunized while $27.5 \%$ were partially and $\mathbf{2 2 . 5} \%$ were not immunized at all. Immunization coverage was highest for BCG (62.5\%) and lowest for measles (39.2\%). Dropout rates were 37.3\%, $19.7 \%$ and $18.2 \%$ for BCG to measles, DPT1 to DPT3 and OPV1 to OPV3 respectively. Vitamin A prophylaxis showed a decline from $38.3 \%$ to $16.7 \%$. Amongst the various reasons for not immunizing the child, the most common in both rural (78.7\%) and urban areas (28.6\%) was lack of awareness for the need of vaccination. However in rural areas lack of availability of services (87.2\%) was the major cause for not immunizing the child.

\section{Conclusion}

The present study shows a low coverage of immunization and Vitamin A prophylaxis in both rural and urban areas. Important reasons for non-immunization were lack of awareness about vaccination and availability of immunization services in rural areas and urban areas.

\section{Key Words}

Immunization coverage, Children between 12-23months, Vitamin A Prophylaxis.

\section{Background}

The current scenario depicts that immunization coverage has been steadily increasing but the average levels remain far less than desired. Still only $44 \%$ of infants in India are fully immunized (NFHS III), which is much less than the desired goal of achieving $85 \%$ coverage ${ }^{1}$. Because of increased accessibility of health care services in both urban and rural areas, an increase was expected in the utilization of the immunization services. However, studies reveal that utilization of health care services including $\mathrm{MCH}$ services ${ }^{2}$ is low all segments of the society. Slums are high-risk areas where there is a communicable disease transmission and about $25 \%$ of the Indian urban poor currently live in slums. Maternal and child health indicators among slum people show that their health is 2-3 times worse than those of people living in other urban areas. ${ }^{3}$ Of the 10 million children who died during 2004, over 2.5 million children $(25 \%)$ died from vaccine preventable diseases ${ }^{4}$. This means that most of these child deaths could have been prevented 
by immunization. Immunization is a proven cost-effective and relatively inexpensive public health intervention for improving child survival. Under the National Immunization Programme, infants are immunized against six vaccine preventable diseases namely tuberculosis, diphtheria, pertussis, poliomyelitis, measles and tetanus. During the years, in most parts of India recombinant Hepatitis vaccine has been introduced. According to UNICEF report India ranks $49^{\text {th }}$ in child mortality rate. About 2.4 million Indian children perished due to pneumonia, diarrhea, measles, tetanus and whooping cough. Rajasthan, Uttar Pradesh, Madhya Pradesh accounts for more than 50 percent of these infant deaths in India ${ }^{5}$. Though immunization is one of the most effective public health to improve child survival, statistics shows an alarming trend. Immunization has been declining for last two decades. The reported coverage has been above 80 percent since $1990^{6}$. However, UNICEF Report (2004) revealed that only 57 percent of children aged 12-23 months were fully immunized in India ${ }^{7}$. The recent information about information about immunization coverage for Bareilly district is lacking. Therefore we carried out a survey in Bareilly district of western Uttar Pradesh a North Indian State. We aimed to assess the immunization status of children in the age group of 12-23 months and to know the reported reasons for not immunizing the children.

\section{Materials and Methods}

We carried out a cross-sectional study using WHO's thirty cluster sampling technique. Twenty-one clusters were selected from rural areas and nine from urban areas of Bareilly district to obtain a proportionate allocation from rural and urban population. Rural areas were divided into blocks and blocks were divided into villages. Urban areas were divided into wards. Each of the villages and wards were considered as clusters. The survey was carried out from August 2008 to January 2009. Within each selected clusters, we selected the households by random technique by moving in the direction indicated turning a bottle. We surveyed all the houses in the chosen direction until a minimum of seven eligible children i.e. children in the age group of 12-23 months were achieved (as the target for each cluster was seven). This age group was chosen as Immunization status of children aged between 1-2 years gives a better picture of immunization coverage according to Universal Immunization Program (UIP) norms. In the sample of children surveyed there were 161 children living in rural and 79 children living in urban areas. A total of 240 mothers having children in the age group of $12-23$ months were surveyed to provide information regarding immunization status of their children. A total of two teams (each with one faculty member and two health workers) did the survey using a structured and pretested questionnaire. The questionnaire contained information to be asked about demographic, immunization status and reasons reported by mother for not immunizing the child. Fully immunized means the children received all the doses of vaccines as per Universal Immunization Programme (UIP) till that age and partially immunization means children not received all doses as per UIP and not immunized at all refer those children who not received any vaccines The data gathered was analyzed by using SPSS package version 14.0 we calculated rates of immunization coverage and proportions for immunization status of children for each of vaccines under EPI program. We used appropriate statistical test of significance. A p-value of less than 0.05 was considered as significant.

\section{Results}

Out of total 240 children covered during the survey, immunization cards were available for 179 (74.6\%) children. For the remaining children, immunization status was ascertained by mother's recall.

Table I: Immunization Status of Children between 12-23 months

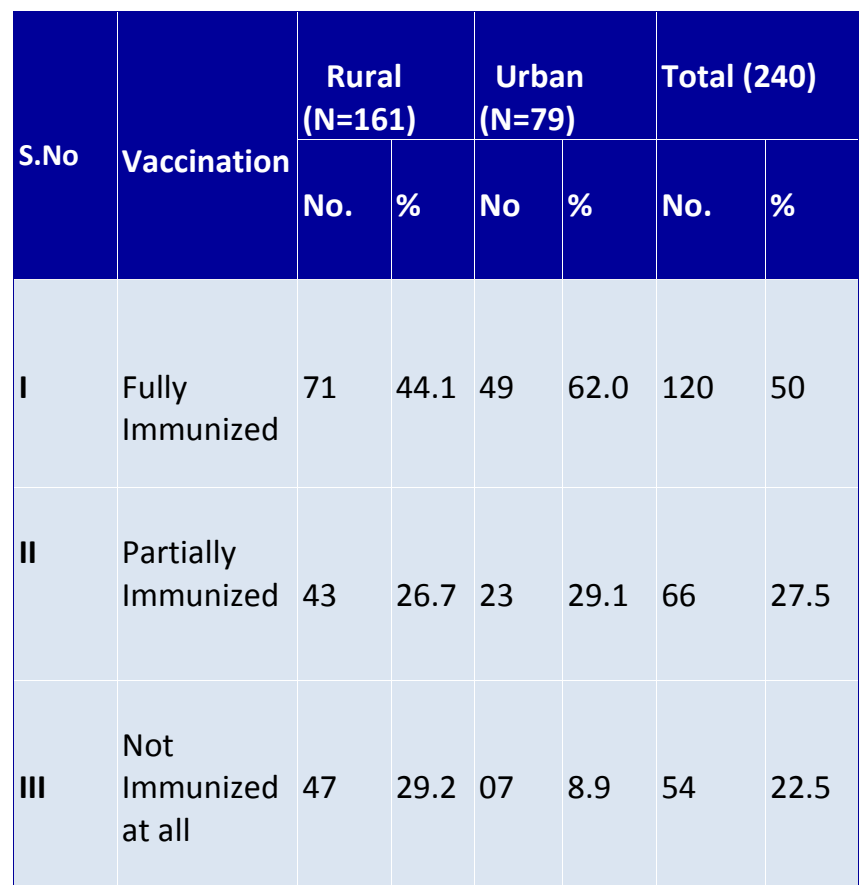

Chi square $=6.81, p=0.00905$

Only 120 (50\%) children were fully immunized. This rate was $44.1 \%$ in rural areas and $62.0 \%$ in urban areas. The rest were either partially immunized $(27.5 \%)$ or not immunized at all $(22.5 \%)$. The percentage of non-immunized were $29.2 \%$ in rural and only $08.9 \%$ in urban areas this difference is statistically significant $\left(X^{2}=6.81, p=0.00905\right)$ as shown in Table-I.

Among individual vaccines, coverage was highest for BCG (62.5\%) and lowest for measles (39.2\%). Coverage for DPT 3 and $\mathrm{OPV}_{3}$ was almost the same (47.5\% and $\left.48.8 \%\right)$. Only 92 $(38.3 \%)$ children $n$ had received Vitamin A supplements at the time of measles vaccination. A consistent decline in coverage rates from the first to third dose was observed for DPT and OPV both in urban and rural areas. DPT and OPV dropout rates from the first to third dose were $19.7 \%$ and $18.2 \%$, respectively. These rates were $22.8 \%$ and $20.3 \%$ respectively for rural and $15.9 \%$ and $15.6 \%$ for urban areas. 
The dropout rate for measles compared with BCG and DPT 1 were $37.3 \%$ and $33.8 \%$ respectively in rural and urban areas as shown in Table II.

Table II: Immunization Status and dropout rates of Children between 12 to 23 months of Age

\begin{tabular}{|c|c|c|c|c|c|c|c|}
\hline \multirow[t]{2}{*}{ S.No } & \multirow{2}{*}{$\begin{array}{l}\text { Vaccina } \\
\text { tion }\end{array}$} & \multicolumn{2}{|c|}{$\begin{array}{l}\text { Rural } \\
\text { (N=161) }\end{array}$} & \multicolumn{2}{|c|}{$\begin{array}{l}\text { Urban } \\
(N=79)\end{array}$} & \multicolumn{2}{|c|}{ Total (240) } \\
\hline & & No & $\%$ & No & $\%$ & No & $\%$ \\
\hline I & BCG & 73 & 51.6 & 67 & 84.8 & 150 & 62.5 \\
\hline II & DPT-1 & 79 & 49.1 & 63 & 79.8 & 142 & 59.2 \\
\hline III & DPT-2 & 67 & 41.6 & 59 & 74.7 & 126 & 52.5 \\
\hline IV & DPT-3 & 61 & 37.9 & 53 & 67.1 & 114 & 47.5 \\
\hline v & Polio-1 & 79 & 49.1 & 64 & 81.0 & 143 & 59.6 \\
\hline VI & Polio-2 & 68 & 42.2 & 59 & 74.5 & 127 & 52.9 \\
\hline VII & Polio-3 & 63 & 39.1 & 54 & 68.4 & 117 & 48.8 \\
\hline VIII & Measles & 43 & 26.7 & 51 & 64.6 & 94 & 39.2 \\
\hline IX & VitA-1 & 43 & 26.7 & 49 & 62.0 & 92 & 38.3 \\
\hline$x$ & VitA-2 & 21 & 13.0 & 43 & 54.4 & 64 & 26.7 \\
\hline $\mathbf{X I}$ & VitA-3 & 11 & 6.8 & 29 & 36.7 & 40 & 16.7 \\
\hline \multicolumn{2}{|c|}{$\begin{array}{c}\text { Drop Out } \\
\text { Rates }\end{array}$} & \multicolumn{2}{|c|}{ Rural\% } & \multicolumn{2}{|c|}{ Urban\% } & \multicolumn{2}{|c|}{ Total\% } \\
\hline \multicolumn{2}{|c|}{$\mathrm{DPT}_{1}$ to $\mathrm{DPT}_{3}$} & \multicolumn{2}{|c|}{22.8} & \multicolumn{2}{|c|}{15.9} & \multicolumn{2}{|c|}{19.7} \\
\hline \multicolumn{2}{|c|}{$\mathrm{OPV}_{1}$ to OPV 3} & \multicolumn{2}{|c|}{20.3} & \multicolumn{2}{|c|}{15.6} & \multicolumn{2}{|c|}{18.2} \\
\hline \multicolumn{2}{|c|}{$\begin{array}{l}\mathrm{DPT}_{1} \text { to } \\
\text { Measles }\end{array}$} & \multicolumn{2}{|c|}{45.6} & \multicolumn{2}{|c|}{19.1} & \multicolumn{2}{|c|}{33.8} \\
\hline
\end{tabular}

Table III shows the various reasons reported by the mother for not immunizing the child. The most frequently reported reason in both rural (78.7\%) and urban areas (28.6\%) was unawareness for the need of vaccination. However, in rural areas lack of availability of services (87.2\%) was the main reason reported for not immunizing the child.

Table III: Details Pertaining to Immunization of Children 12-23 months of age

\begin{tabular}{|c|c|c|c|c|}
\hline \multirow{2}{*}{ S.No } & \multirow{2}{*}{$\begin{array}{l}\text { Reason for } \\
\text { not } \\
\text { immunizing } \\
\text { the } \\
\text { Child }\end{array}$} & $\begin{array}{l}\text { Rural } \\
N=47\end{array}$ & $\begin{array}{l}\text { Urban } \\
N=07\end{array}$ & $\begin{array}{l}\text { Total } \\
N=54\end{array}$ \\
\hline & & No(\%) & No (\%) & No (\%) \\
\hline I & $\begin{array}{l}\text { Child too } \\
\text { young for } \\
\text { immunization }\end{array}$ & $6(12.8)$ & $0(0.0)$ & $6(11.1)$ \\
\hline II & $\begin{array}{l}\text { Unaware for } \\
\text { the need of } \\
\text { immunization }\end{array}$ & $\begin{array}{l}37 \\
(78.7)\end{array}$ & $2(72.7)$ & $39(72.2)$ \\
\hline III & $\begin{array}{l}\text { Place and } \\
\text { time of } \\
\text { immunization } \\
\text { not known }\end{array}$ & $\begin{array}{l}19 \\
(40.4)\end{array}$ & 1 (14.3) & $20(37.0)$ \\
\hline IV & $\begin{array}{l}\text { Fear of side } \\
\text { effects }\end{array}$ & $\begin{array}{l}14 \\
(29.8)\end{array}$ & 1 (14.3) & $15(27.8)$ \\
\hline v & $\begin{array}{l}\text { No faith in } \\
\text { immunization }\end{array}$ & $2(4.3)$ & $1(14.3)$ & $3(5.6)$ \\
\hline VI & $\begin{array}{l}\text { Services not } \\
\text { within reach }\end{array}$ & $\begin{array}{l}41 \\
(87.2)\end{array}$ & $0(0.0)$ & 41 (75.9) \\
\hline VII & $\begin{array}{l}\text { Family } \\
\text { problems }\end{array}$ & $2(4.3)$ & $1(14.3)$ & $3(5.6)$ \\
\hline
\end{tabular}

\section{Discussion}

Out of total 240 children of age group 12-23 months only $50 \%$ were fully immunized and $22.5 \%$ were non-immunized. As per NFHS $\mathrm{II}^{1}$, only $23 \%$ children were fully immunized in UP and $33.6 \%$ was not immunized at all. Kar M et al $(2001)^{9}$ in their study in a slum of Delhi and R J Yadav et al (2004) ${ }^{10}$ in the State of MP reported a higher percentage (above $60 \%$ ) of fully immunized children but Sharma R et al $(2009)^{8}$ in slums of Surat reported only $25.1 \%$ children of age group 12-23 months were fully immunized and $23.1 \%$ not immunized at all. As per a Report of Govt. of UP $(2007)^{11}$, only $39.4 \%$ children aged $12-23$ months are found to be fully immunized and $33.4 \%$ partially immunized.As per NFHS $\mathrm{III}^{1}$, BCG coverage in UP was 61\% (Urban 66.6\% Rural 59.6\%). In present study BCG coverage was observed $62.5 \%$ (Urban $84.8 \%$ and Rural $51.6 \%$ ). It was lower than as reported by Sharma R et al $(2009)^{8} 75.1 \%$. As per NFHS III ${ }^{1}, \mathrm{DPT}_{3}$ and $\mathrm{OPV}_{3}$ were given to $30 \%$ and $87.6 \%$ children of age group of $12-23$ months respectively in UP. In present study it is given to $47.5 \%$ (67.1\% Urban and $37.9 \%$ Rural) $48.8 \%(68.4 \%$ 
Urban and $39.1 \%$ Rural) children, while Sharma $\mathrm{R}$ et al $(2009)^{8}$ reported $\mathrm{DPT}_{3}$ and $\mathrm{OPV}_{3} \quad 48.6 \%$ and $47.9 \%$ respectively in slums of Surat. In present study measles coverage was observed $39.2 \%$ (64.6\% in Urban and $26.7 \%$ in Rural areas) it was higher than reported by Sharma $\mathrm{R}$ et al $(2009)^{8} 29.9 \%$. Dropout rates observed in present study were $37.3 \%, 19.7 \%$ and $18.2 \%$ for BCG to measles, $\mathrm{DPT}_{1}$ to $\mathrm{DPT}_{3}$ and $\mathrm{OPV}_{1}$ to $\mathrm{OPV}_{3}$ respectively, it was much lower than reported by Sharma R et al (2009) $)^{8} 60.2 \%, 31.9 \%$, and $31.5 \%$ for BCG to measles, DPT ${ }_{1}$ to DPT ${ }_{3}$, and OPV ${ }_{1}$ to OPV ${ }_{3}$ respectively. The three doses of Vitamin $A$ prophylaxis showed a decline from $26.7 \%$ to $6.8 \%$ in rural and $62.0 \%$ to $36.7 \%$ in urban areas. In a study by Chaturvedi et al $(2007)^{12}$ in Agra district, only $13.8 \%$ (12.9\% and $15.4 \%$ in rural and urban areas respectively) children had received first dose of vitamin-A along with measles. Important reasons for nonimmunization were lack of awareness in both the Urban (28.6\%) and Rural (78.6\%) areas and lack of availability of services in rural areas (87.2\%). In a study by Nandan et al $(1996)^{13}$ and Chaturvedi $\mathrm{M}$ et al $(2007)^{12}$, non availability of services was reported to be the single commonest reason for non-immunization.

\section{Conclusion and Recommendations}

The present study shows a lower coverage of immunization and Vitamin A prophylaxis than as recommended in both the urban and rural areas. Coverage for fully immunized children was primarily low due to measles. Important reasons for non-immunization were lack of awareness in both the areas and lack of availability of services in rural areas. It can be advised that some health care packages under maternal and child health $(\mathrm{MCH})$, such as family planning counseling, iron, folic acid or vitamin $A$ supplementation, or the provision of iodized salt can be given to attract parents especially to sustain contact for the time between DPT ${ }_{3}$ and Measles vaccinations and to hold the parents attention during non immunization periods and also to contribute toward the health status of the mother and children. Renewed interest should be developed both in local health functionaries and beneficiaries to accelerate the optimization of immunization services. The $\mathrm{RCH}$ program for immunization should revise its strategy to increase the utilization of services by all segments of the population. Improvement should focus on bottlenecks by reducing the dropout rate from DPT ${ }_{2} / \mathrm{OPV}_{2}$ to DPT3 / OPV 3 and improving coverage of measles (and also Vitamin A). The remaining deficiency may be overcome by generating awareness among the community by holding mother's meetings and extensive IEC programs, inviting opinions and suggestions from them, and enhancing community participation $^{8,14}$.

\section{Conflict of Interests}

The authors do not have any conflict of interest arising from the study.

\section{References}

1. International Institute for Population Sciences (IIPS) and Macro International. 2007. National Family Health Survey (NFHS-3), 2005-06, India: Key Findings. Mumbai: IIPS.

2. Venkatesh RR, Umerkantha AG, Yuvaraj J. Safe motherhood status in the urban slums of Davangere city. Indian J Community Med 2005;30:6-7.

3. Rao BT, Thakur JS. Vulnerability assessment in slums of union territory, Chandigarh. Indian J Community Med 2007;32(3):189-91.

4. Miller R, Mishrif A. The Barcelona process and Euro-Arab economic relations,1995-2005: Middle East Review of International Affairs 2005; 9(2).94-108.

5. Statesman $7^{\text {th }}$ April 2005

6. Measles mortality reduction. India Strategic Plan20052010. Ministry of Health and FamilyWelfare, Government of India.http://www.whoindia.org/LinkFiles/ Measles_Measles pdf.pef. Accessed on November 13, 2008.

7. UNICEF, Mapping India's Children, UNICEF in Action, 2004; 62-3.

8. Sharma R, Desai VK, Kavishvar A. Assessment of immunization status in the slums of Surat by 15 clusters multi indicators cluster survey technique. Indian J Community Med 2009 ; 34(2): 152-5.

9. Kar M, Reddaiah VP, Kant S. Primary immunization status of children in slum areas of South Delhi - The challenge of reaching the urban poor. Indian J Community Med 2001; 26(3): 151-4.

10. Yadav JR, Singh P. Immunization status of children and mothers in the state of Madhya Pradesh. Indian J Community Med 2004;29(3).

11. Ahmad J, Khan ME, Hazra A. Increasing complete immunization in rural Uttar Pradesh: The Journal of Family Welfare 2010;56,65-72.

12. Chaturvedi M, Nandan D, Gupta SC. Rapid assessment of immunization practices in Agra District. Indian J Public Health 2007;51(2):132-4.

13. Nandan D, Dabral SB, Report-Multi Indicator Rapid Assessment Survey (Uttar Pradesh)-District Etah, Mathura and Almorah Department of SPM, SN Medical College,Agra,1995-96.

14. Swami HM, Thakur JS, Bhatia SPS, Bhatia V, Bhan VK. Coverage evaluation survey of pulse polio immunization in Chandigarh. Indian J Community Med 2000;25(2): 83-5. 